\title{
Prevalence of Mental Disorders and Health Service Utilization among Individuals with Turkish Migration Backgrounds in Germany: A Study Protocol for an Epidemiological Investigation
}

\author{
Mike Mösko1 ${ }^{*}$, Demet Dingoyan ${ }^{1 * \#, ~ S i m o n e ~ P e n k a ², ~ A z r a ~ V a r d a r ~}{ }^{2}$, Holger Schulz ${ }^{1}$, \\ Uwe Koch', Andreas Heinz ${ }^{2}$, Ulrike Kluge ${ }^{2,3}$ \\ ${ }^{1}$ Department of Medical Psychology, University Medical Center Hamburg-Eppendorf, Hamburg, Germany \\ ${ }^{2}$ Clinic for Psychiatry and Psychotherapy, Charité-University Medicine Berlin, Germany \\ ${ }^{3}$ Department of Migration, Mental and Physical Health and Health Promotion, BIM-Berlin Institute for \\ Empirical Integration and Migration Research, Humboldt University zu Berlin, Berlin, Germany \\ Email: mmoesko@uke.de, "d.dingoyan@uke.de, simone.penka@charite.de, azra.vardar@charite.de, \\ schulz@uke.de,koch@uke.de, andreas.heinz@charite.de,ulrike.kluge@charite.de
}

Received 26 May 2016; accepted 26 July 2016; published 29 July 2016

Copyright (C) 2016 by authors and Scientific Research Publishing Inc.

This work is licensed under the Creative Commons Attribution International License (CC BY). http://creativecommons.org/licenses/by/4.0/

(c) (7) Open Access

\footnotetext{
Abstract

Background: There is a lack of reliable epidemiological data on prevalence and comorbidity rates of mental disorders in the migrant population in Germany. Despite existing national and international data on the extent of psychosocial burdens in migrant populations the prevalence among the study population remains unclear. The aim of this study was to collect prevalence data for the largest migrant population in Germany-individuals with Turkish migration backgrounds-using a culturally and linguistically sensitive approach. Methods: The study employs a cross-sectional design. The multi-centre study (Hamburg, Berlin) is based on a sample of individuals with Turkish migration backgrounds living in the two cities stratified by age, gender, and education. The study programme consists of three phases: 1) a qualitative focus group to collect information on how to increase the participation rate of the target population as a minority group in Germany; 2) a translation phase to create culture and linguistic sensitive versions of the assessment tools (e.g., the Composite International Diagnostic Interview (CIDI) for Turkish speaking individuals; and 3) a baseline community study to assess the lifetime, 12-month and four-week prevalence and comor-

*These authors contributed equally to this work.

\#Corresponding author.

How to cite this paper: Mösko, M., Dingoyan, D., Penka, S., Vardar, A., Schulz, H., Koch, U., Heinz, A. and Kluge, U. (2016) Prevalence of Mental Disorders and Health Service Utilization among Individuals with Turkish Migration Backgrounds in Germany: A Study Protocol for an Epidemiological Investigation. Open Journal of Psychiatry, 6, 237-252.

http://dx.doi.org/10.4236/ojpsych.2016.63029
} 
bidity rates of mental disorder, health care utilization and help-seeking behaviour in individuals of Turkish migration backgrounds living in Germany. Discussion: The study provides important data on the lifetime prevalence of mental disorders and health care utilization of individuals with Turkish migration backgrounds. Furthermore, the study is an important step towards gaining a better understanding of potential barriers to participation, creating resources for difficult-toreach minorities, and understanding the need for assessing mental disorders in migrant populations. These results can offer a starting point for the initiation of the necessary structural changes for mental health care services and policies for groups with migration backgrounds.

\section{Keywords} Mental Health, Mental Disorder, Migration, Turkish, Germany, Prevalence, Comorbidity, Health
Care Utilization, Composite International Diagnostic Interview (CIDI), Epidemiology

\section{Background}

The number of migrants in the world has more than doubled since 1980, with most migrants living in Europe (72.4 million), Asia (70.8 million) and North America (53.1 million) [1]. In the 27 European Union (EU) member states, there are currently 50.2 million foreign-born residents, constituting up to $9.9 \%$ of the total population [2], of which 3.1 million are recognized refugees and 605,689 are considered stateless people [3].

Mental illness is a leading cause of suffering, economic loss and psychosocial problems, accounting for over $15 \%$ of the disease burden in developed countries, a figure higher even than the disease burden caused by cancer [4]. According to [5], approximately 38\% of the European population suffers from a mental illness. Detailed knowledge about the mental health of migrants in Europe is limited [6] [7] because migrants are often excluded from routine surveys [8], resulting in a lack of representative data.

Existing theoretical models regarding the extent of mental distress in migrants come to different conclusions concerning the healthy migrant effect [9], the migration stress hypothesis [10] and the theory of social disparity [11].

A meta-analysis for the association between migration and common mental disorders found a slightly increased risk of developing depressive disorders among migrants, with a mean relative risk of 1.38 (95\% CI 1.17 - 1.62). However, this evidence is mainly drawn from incidence studies, using data acquired during initial hospital admission [12].

Population-based epidemiological studies in the USA found lower rates of mental disorders among different migrant groups in comparison to their host society. Such patterns have been reported for Mexican and other Hispanic migrants [13] [14], Asians [15] [16] and non-Hispanic white immigrants [13]. However, that initial advantage in mental health decreases over time, and a longer length of migrant residency is associated with a higher risk of mental illness [17] [18]. In a Swedish cohort study, risk ratios for all ethnic minorities were diminished (and virtually eliminated among non-Europeans) by adjusting for socioeconomic differences [19].

Regarding the Turkish migrant population, epidemiological studies have found a higher psychopathological burden compared to the host society in Belgium [20] and in the Netherlands [21] [22].

Current research on migration and mental health in Germany is hampered by a fundamental lack of representative data on migrants' mental health status and their access to and use of treatment options [23] [24]. A reanalysis of the Federal Health Survey [25] did reveal higher prevalence rates of mental disorders for migrants with foreign citizenship and foreign birthplace in comparison to Germans, with the limitation that only German speaking people could participate in the study.

Glaesmer et al. (2009) [26] also conducted a representative population survey, but found no significant differences in the prevalence of mental disorders of migrants compared to the native population. However, the representativeness of this sample for migrants living in Germany is rather limited because only those who were more integrated and had moderate or high level German language skills participated.

To assess the prevalence rates and comorbidity of mental disorders in the target population, we conducted a bilingual epidemiological survey focusing on one of the largest (currently approximately 3 million) migration 
groups in Germany: individuals with Turkish migration backgrounds [27].

Each research question (RQ) derived from this study is given a number and listed below:

RQ 1: How feasible is the translated Turkish version of the standardized, clinically structured interview (CIDI DIA-X Version 2.8TR)?

RQ 2: What are the point, year and lifetime prevalence rates of mental disorders among individuals with Turkish migration backgrounds?

RQ 3: What are the comorbidity rates of mental disorders among individuals with Turkish migration backgrounds?

RQ 4: What is the relationship of the prevalence to symptom severity, risk factors and health service utilization?

RQ 5: What are the barriers, resources and possible methodological approaches to increase the participation of individuals with Turkish migration backgrounds in health research studies?

\section{Methods/Design}

\subsection{Study Design}

This epidemiological multi-centre study, pertaining to the prevalence of psychosocial distress, mental disorders and the need for treatment in individuals with Turkish migration backgrounds, was carried out in the two centres of Hamburg (November 21, 2011-July 15, 2012) and Berlin (July 7, 2011-July 15, 2012).

To identify barriers to participation in the target group and to improve the survey participation rate, several focus groups with individuals with Turkish migration backgrounds were conducted [28]. After conducting a comprehensive research of available survey material, selected interview instruments (i.e., the computerized Composite International Diagnostic Interview, Diagnostic Expert System Interview, shortened: CIDI DIA-X Version 2.8 and questionnaires were subsequently translated into Turkish [29].

The planning and implementation of the survey was aided by numerous multipliers and key persons in Hamburg and Berlin, whose support information regarding the study and ongoing interviews was communicated to Turkish communities in those two cities.

Initially, recruiting study participants was supposed to be a uniform process in both Hamburg and Berlin; however, due to privacy protection laws in Berlin-which are particularly strict regarding sampling of individuals from minority groups-a registry based recruitment method in combination with an onomastic procedure was not possible. Therefore, two slightly different recruitment designs were implemented in Hamburg and Berlin.

In Hamburg, a regional market research institute with expertise in epidemiological interviews (BIK Aschpurwis + Behrens $\mathrm{GmbH}$ ) was commissioned to coordinate and implement the interviews. In the final phase of the data collection process (May 2012-July 2012), snowball sampling was additionally applied, due to limited participation rates.

In Berlin the recruitment took place through on-site surveys in public places and through snowball sampling.

To facilitate participation, community-based survey offices were established in both research centres. The participants could freely choose the language in which they preferred the interviews to be conducted (Turkish or German).

\section{Sample recruitment}

In Hamburg, a random sampling of the regional population register took place in the first stage. The criteria for selecting the Hamburg districts (see Table 1) were the quantity and density of the Turkish migrant population in the respective districts [30].

A total of 7239 individuals with Turkish citizenships and corresponding addresses could be identified. For a further nearly 50,000 individuals with German citizenships an onomastic procedure was applied [31]. This was based on a name algorithm, which identifies individuals of Turkish backgrounds based on their first and last names. With the help of this onomastic procedure, an additional 3098 individuals with Turkish migration backgrounds (included German citizenships) were identified. A total sample of 10,837 addresses were acquired from the citizen registration office.

The selected individuals were contacted by mail. A random selection of the 7239 addresses of the individuals with Turkish citizenship were contacted in two postal waves, five weeks apart. The individuals identified through the onomastic procedure were contacted in a third wave one month later. All 10,837 people also received a timely 
Table 1. Random sampling based on registration office data in Hamburg.

\begin{tabular}{|c|c|c|c|c|}
\hline City districts & $\begin{array}{l}\text { Individuals with Turkish migration } \\
\text { backgrounds (Age:18-65): Number } \\
\text { of requested addresses }\end{array}$ & $\begin{array}{l}\text { Number of } \\
\text { addresses } \\
\text { received }\end{array}$ & $\begin{array}{l}\text { Individuals with German } \\
\text { citizenships (Age:18-65): Number } \\
\text { of requested addresses }\end{array}$ & $\begin{array}{c}\text { Number of } \\
\text { addresses } \\
\text { received }\end{array}$ \\
\hline \multicolumn{5}{|l|}{ Area 1} \\
\hline Rothenburgsort & 250 & 250 & 1700 & 1697 \\
\hline Veddel & 250 & 250 & 1700 & 1699 \\
\hline Wilhelmsburg & 1600 & 1599 & 10700 & 10690 \\
\hline Waltershof/Finkenwerder & 200 & 200 & 1300 & 1300 \\
\hline Harburg & 700 & 700 & 4700 & 4688 \\
\hline Wilstorf & 250 & 250 & 1700 & 1695 \\
\hline Marmstorf & 100 & 100 & 700 & 702 \\
\hline Eißendorf & 300 & 300 & 2000 & 1999 \\
\hline Heimfeld & 350 & 350 & 2300 & 2300 \\
\hline Hausbruch & 250 & 250 & 1700 & 1701 \\
\hline Subtotal of area 1 & 4250 & 4249 & 28500 & 28471 \\
\hline \multicolumn{5}{|l|}{ Area 2} \\
\hline Altona-Altstadt & 550 & 551 & 3700 & 3692 \\
\hline Sternschanze & 180 & 180 & 1200 & 1200 \\
\hline Altona-Nord & 450 & 448 & 3000 & 2988 \\
\hline Ottensen & 450 & 450 & 3000 & 2991 \\
\hline bahrenfeld & 400 & 400 & 2700 & 2693 \\
\hline Groß Flottbek & 120 & 39 & 800 & 799 \\
\hline Othmarschen & 120 & 22 & 800 & 795 \\
\hline Lurup & 550 & 550 & 3700 & 3696 \\
\hline Osdorf & 350 & 350 & 2300 & 2298 \\
\hline Subtotal of area 2 & 3170 & 2990 & 21200 & 21152 \\
\hline Total & 7420 & 7239 & 49700 & 49,623 \\
\hline
\end{tabular}

reminder, which again called attention to the study (see Table 2).

Due to the low response rate (average 2.5\%) of the initial contact and consequent reminders, an additional 320 consent forms from participating individuals were obtained through snowball sampling (see Table 3 ). The recruitment was based on a national quota scheme, which was achieved through targeted sampling of the population registry, focusing on individuals with Turkish migration backgrounds (personal communication with micro-census staff, 2012). This included a total of six strata consisting of the variables gender (male and female) and age (age groups: 18 - 34, 35 - 49, and 50 - 65).

In the final data collection phase (July 6, 2012-July 15, 2012), individuals were recruited for those age and gender strata that had insufficient numbers of participants.

In Berlin, the sample recruitment took place through on-site collection and snowball sampling. To approximate a representative sample, a quota scheme was applied based on population-based microcensus data of 2009 including individuals with Turkish migration backgrounds in Berlin. The quota scheme included a total of 24 fields with the following characteristics: gender, age (18 - 49 and 50-older), education (primary school, secondary school level I certificate, final secondary school examination/university entrance or diploma, no graduation, still in school/training).

During the recruitment phase, contact was made with several key persons with Turkish migration backgrounds within the Turkish community in Berlin. This was done to gain access to potential participants and to 
Table 2. Overview of the initial contact and consequent reminders in Hamburg.

\begin{tabular}{|c|c|c|c|c|}
\hline & \multicolumn{2}{|c|}{ Initial contact } & \multicolumn{2}{|c|}{ Reminders } \\
\hline & Date & Letter & Date & Letter \\
\hline Total & & 10,837 & & 10,422 \\
\hline \multirow{2}{*}{ 1) Wave, registration office data } & \multirow{2}{*}{ 07.11.2011 } & \multirow{2}{*}{4143} & 07.02 .2012 & 1500 \\
\hline & & & 14.02 .2012 & 2379 \\
\hline \multirow{2}{*}{ 2) Wave, registration office data } & \multirow{2}{*}{ 16.12.2011 } & \multirow{2}{*}{3621} & 21.02.2012 & 1635 \\
\hline & & & 28.02.2012 & 1881 \\
\hline \multirow{2}{*}{ 3) Wave, registration office data (+Onomastic) } & \multirow{2}{*}{ 24.01.2012 } & \multirow{2}{*}{3073} & 05.04 .2012 & 1346 \\
\hline & & & 23.04.2012 & 1681 \\
\hline
\end{tabular}

Table 3. Participation agreement (via consent forms) through snowball sampling in Hamburg.

\begin{tabular}{ccc}
\hline Total & Date/Timeframe & Consent \\
\hline Cultural event & & 320 \\
Friday prayer in mosque & 29.01 .2012 & 36 \\
Club celebrations in mosque "kermes” & 27.04 .2012 & 96 \\
Music event & $04 .-06.05 .2012$ & 49 \\
Specific recruitment based on the quota plan & 10.06 .2012 & 29 \\
Other (i.e., through interviewers) & $06 .-15.07 .2012$ & 28 \\
\hline
\end{tabular}

identify appropriate locations for on-site interviews. To establish formal and informal networks, several community-based activities were initiated including workshops, public discussions, focus groups, discussions with stakeholders etc. In an initial step, the research group decided to recruit at weekly markets and citizen registration offices. After the initial data collection phase, it became evident that young men in particular were inadequately represented. As a result, individuals were recruited from a college, a mosque and at father meetings, as they are called in Germany.

The research group in Berlin also based the data collection on the two city districts with the highest number and density of individuals with Turkish migration backgrounds (Berlin-Wedding and Berlin-Neukölln).

To supplement the recruitment phase, the research team was able to gain access to a Berlin-based multiplier project, which enabled many individuals of Turkish migration backgrounds to be made aware of the survey.

The preliminary survey (which consisted of screening questions, the collection of sociodemographic data and data regarding the use of healthcare services) took place in public places (see Table 4). Here, the participants signed consent forms for the study. At this stage, two possibilities were offered for participation in the main survey (the clinically structured interview via CIDI DIA-X Version 2.8TR). Participants could either schedule an appointment directly at that point, or call in at a later time to a bilingual-staffed telephone hotline set up for this study to arrange an appointment.

\section{Criteria for (non-)participation}

Inclusion criteria: For the study, all adults (between 18 and 65 years) living in Hamburg and Berlin who had a Turkish migration background were possibly eligible; however, the following inclusion criteria also had to be fulfilled: First, the participants had to agree to the survey setting, which consisted of face-to-face interviews where no third-party participants were permitted. In addition, a degree of independent mobility was required of the participants, who had to come to the interview offices. House visits were not implemented. The participants had to sign a consent form agreeing to participate in the study. In Berlin, it was additionally necessary to take part in a preliminary survey, as described previously.

Exclusion criteria: Individuals whose migration background was not Turkish, who were not adults (>18 years old) or were over the age of 65 were not included in the study. 
Table 4. Participation in the preliminary survey in Berlin, sorted by data collection onsite.

\begin{tabular}{ccc|}
\hline Data collection on-site & Survey timeframe/date & Number of preliminary surveys \\
\hline Total & & $\mathbf{6 0 4}$ \\
\hline Pilot project "the bridge” in Berlin-Wedding & $14.07 .2011-15.09 .2011$ & 9 \\
Municipal office in Berlin-Wedding & $19.07 .2011-26.01 .2012$ & 135 \\
Weekly market in Berlin-Wedding & $20.07 .2011-30.11 .2011$ & 233 \\
Sprengelhaus in Berlin-Wedding & $10.08 .2011-24.04 .2012$ & 7 \\
College in Berlin-Wedding & $11.01 .2012-18.01 .2012$ & 9 \\
Mosque in Berlin-Spandau & 02.12 .11 & 18 \\
Neighbourhood initiative in Berlin-Neukölln & 20.01 .12 & 146 \\
Municipal office in Neukölln & $14.02 .2012-26.06 .2012$ & 22 \\
Music festival in Berlin-Neukölln & $10.03 .2012-14.07 .2012$ & 7 \\
\hline
\end{tabular}

Termination criteria: In individual cases, survey participation was terminated after consultation with the study supervisors, due to poor health issues or severe limitations in understanding or answering the interview questions.

During the interviews, if a strong psychosocial strain was evident, the participants were given informative brochures by the interviewers regarding local psychosocial assistance opportunities in Hamburg and Berlin.

\section{Training of the interviewers and quality assurance}

The interviewers were selected based on their language and social abilities. Therefore, they were tested specifically on their German and Turkish language comprehension and competence by reading passages aloud from the core survey instrument (CIDI DIA-X Version 2.8TR) in both German and Turkish. The selected interviewers were trained over the course of a maximum four day seminar in the following theoretical and practical topics: 1 ) symptoms and diagnoses of mental disorders; 2) study design and data collection process; 3) using the computerized survey instrument (CIDI DIA-X 2.8); 4) the language specifics of the Turkish CIDI DIA-X 2.8TR; 5) practice conducting clinically structured interviews in German and Turkish; 6) handling difficult interview situations (e.g., sadness, anger, suicide); and 7) documentation and study management. The interviewers also had to carry out a full length practice interview, which was discussed on the final training day. Furthermore, they were given a booklet containing guidelines regarding the training contents and a list of questions and answers (frequently asked questions, FAQ) that was updated continuously over the course of the survey. The survey was accompanied by regular supervision sessions (initially conducted weekly and later at 14-day intervals) moderated by two interdisciplinary teams: one in Hamburg (consisting of psychotherapists and a Turkishspeaking psychologist) and the other in Berlin (consisting of a psychologist, a Turkish-speaking ethnologist and an educationalist). Additionally, the interviewers had the opportunity to ask the supervisors questions at any time via telephone or email.

Over the entire data collection time frame, there were a total of 24 bilingual interviewers active in Hamburg (10 females and 4 males) and in Berlin (12 females and 2 males).

\section{Implementation of data collection}

In Hamburg, the research procedure was approved by the ethics committees of the Hamburg chamber of psychotherapists and the privacy data commissioners of the University Hospital Hamburg-Eppendorf. Figure 1 illustrates the survey process in Hamburg.

In Berlin, the research procedure was approved by the ethics committee and the privacy data protection commissioner of the Charité University Medicine-Berlin. Figure 2 illustrates the study design and the two-step survey procedure in Berlin.

\section{Study Information}

In Hamburg, the following bilingual (German and Turkish) documents were mailed to the addresses obtained through the citizen registry random sample: a letter, an informational flyer, a consent form and a prepaid return 


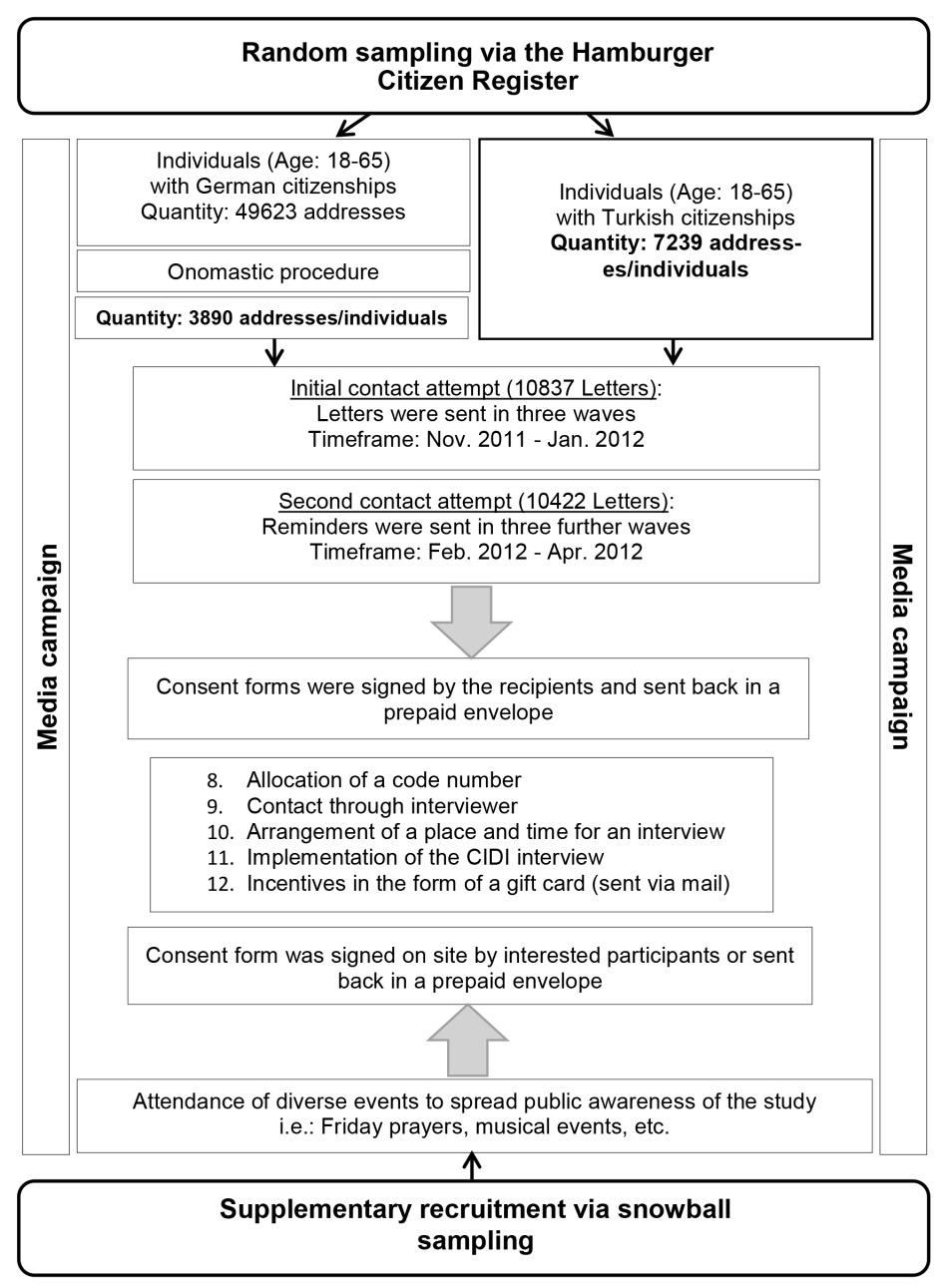

Figure 1. Overview of the data collection in Hamburg.

envelope. In Berlin, the study participants who were recruited in the data collection locations received a bilingual (German and Turkish) informational flyer and a consent form. During the additional snowball sampling in Hamburg and the on-site recruitment in Berlin, the participants had the opportunity to fill out and sign the consent form onsite.

The flyer received by the participants in both cities contained detailed information about the study conditions including the research goals, the interview process, the inclusion criteria, assurance about survey anonymity, and voluntary participation. In addition, the flyer contained contact information and the phone number of the bilingual-staffed information hotline so participants could ask questions. The participants had the option to withdraw from participation at any time without providing any reason or explanation.

Interview Offices and Appointment Coordination

In both cities the interviews took place in rented offices in centrally located districts (Hamburg: Altona, Wilhelmsburg; Berlin: Wedding, Neukölln) that the regionally restricted sample participants could easily access. Interviewers used password-protected databases to coordinate the interviews.

Every interview office also contained password-protected laptops, each with a Turkish and a German version of the CIDI DIA-X 2.8. An update of the output data of the CIDI DIA-X-program was saved on a USB stick daily. The USB sticks containing the output data of the CIDI interviews and all used interview documentation (i.e., contact information, documentation and survey booklets) were collected regularly by the project coordinators.

Preliminary Survey

Due to the regionally adapted recruitment strategy, a preliminary survey was conducted in Berlin. Several 


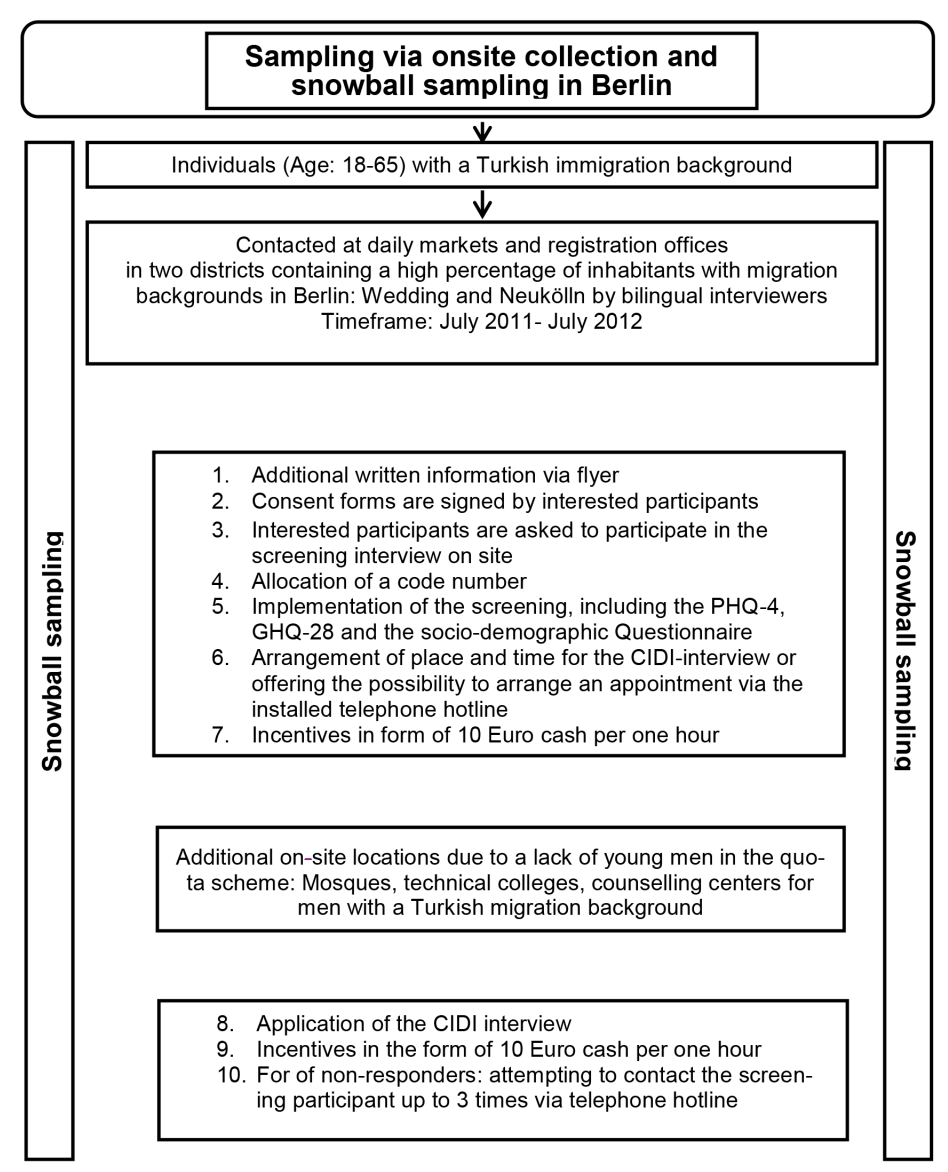

Figure 2. Study design and data collection in Berlin.

booths were set up at the collection sites. Passers-by were directly addressed in Turkish. If they showed interest, they were thoroughly informed about the study, the screening and the two step survey procedure. People who agreed to participate signed the consent forms and were again made aware of the option to withdraw at any time.

The preliminary survey subsequently took place on site and entailed screening instruments (Patient-HealthQuestionnaire, PHQ-4 and General Health Questionnaire, GHQ-28) and a questionnaire concerning sociodemographic data and data pertaining to the use of the healthcare system. After completing the preliminary survey, participants again were informed about the subsequent interview procedure. The appointment for the clinically structured interview was scheduled either onsite or in a follow-up telephone call.

Telephone Contact and Interview Process

In Hamburg, interviewers contacted the participants via telephone to agree upon an interview appointment after they answered two introductory questions and completed a screening via PHQ-4. In Berlin, all participants who did not make an appointment directly after completing the preliminary survey were contacted (at the earliest) two weeks later.

In Hamburg all interviewers were given prepaid cell phones for the duration of the survey period. In Berlin the participants were contacted via a telephone hotline. The participants were reminded of their interview appointment one day in advance via telephone. Upon a participant's request, it was possible to agree on a meeting place close to the interview office (i.e., at a bus or metro station) where the interviewer would pick up the participant. When contact declined to be interviewed, they were asked if they would be willing to answer four (non-responder) closing questions.

Break times during the interview were flexible and were agreed upon as needed. At the end of the interview, the interviewers answered questions to assess the conduction of the interview and the instrument quality on the basis of the last section of the CIDI interview (section x: Interview assessment) and additional documentation sheets. 
The interviewing of friends, relatives or acquaintances was strictly forbidden. In situations where interviewer and participants knew each other from previous contact, alternative interviewers were assigned. Additional reasons for changing the interviewer were 1) the participating person requested a different interviewer (e.g., due to gender) or 2) the interviewer felt uncomfortable conducting the interview.

\section{Drop-Outs}

When participants who had initially agreed to participate via the consent forms did not keep their appointments, they were contacted via telephone over a two-week period, at maximum, eight different times. If contact was not possible or the participant declined to partake in further appointments, they were documented as dropouts.

\section{Data protection}

The interviewers obtained instructions (during their training period) concerning how to maintain data confidentiality. In addition, they were presented with leaflets pertaining to data protection and they were asked to sign a secrecy agreement before beginning the interviews. The instructions took place according to the policies of the following clauses of the German Federal Data Protection Act: 1) identification and handling of all personal data; 2) the obligation of discretion pertaining to trade or business secrets; 3) handling of passwords, media and data files and 4) the use of company internet access and the email system.

The laptops and the study documents were kept in a locked safe in the survey offices. The personal data of the sampled individuals was stored in a safe in the regional coordinator's office and deleted after completing the survey. The original, pseudo-anonymised consent forms will remain with the data protection officers for 10 years.

\section{Data management and control}

In both research centres, data from the documentation sheets, contact sheets and the interview questionnaires were entered by the local research staff. The quality of the entered data was reviewed at regular intervals. Resulting inconsistencies were documented and adjusted.

The output data from the CIDI interviews were edited and sent (password protected) to the Technical University of Dresden (Institute for Clinical Psychology and Psychotherapy) for evaluation. To standardize the editing process in both survey locations, guidelines were developed [29].

Every participant was assigned a two- to five-digit interview code number. These were noted in the contact and documentation sheets and assigned to the interviewees. The interviewers were assigned a two-digit interviewer code number, which was also noted in the documentation and protocol sheets. To conduct the interviews, both code numbers (that of interviewee and the interviewer) had to be noted on the survey documents and entered to start the CIDI DIA-X-program.

\section{Survey instruments}

\section{CIDI DIA-X Version 2.8 (TR)}

The Composite International Diagnostic Interview (CIDI DIA-X Version 2.8) was the core instrument of the survey [29]. The first version of the CIDI was developed in the 1980s, in the context of a cooperative project between the World Health Organization and the former US Alcohol, Drug Abuse, and Mental Health Administration (ADAMHA) [32]. The CIDI is a standardized, clinically structured, face-to-face interview instrument used to determine mental disorders based on the DSM-IV [33] and ICD-10 [34]. The present survey focused on the most common diagnoses in adolescence and adulthood (excluding: personality disorders, dementia, and psychological or behavioural disorders in childhood). Figure 3 shows the diagnostic areas covered by the CIDI DIA-X Version (in German and Turkish). The psychometric quality criteria with respect to objectivity, reliability and validity proved to be good [32] [35] [36].

The average completion time for the CIDI DIA-X Version 2.8 TR used in this study was 117 minutes.

\section{PHQ-4}

The Patient-Health-Questionnaire (PHQ-4), is an ultra-short version of the German full version (PHQ-D) and is composed of a two-item depression scale (PHQ-2) and a two-item general anxiety scale (GAD-2). The items were rated on a 4-point Likert-scale where $0=$ ("not at all"), 1 = ("several days"), 2 = ("more than half the days"), and 3 = ("nearly every day"). The ratings for these four items were totalled for each individual. With a maximum possible total score of 12 points, a score of 6 or more points suggested the possibility of depression or an anxiety disorder. The PHQ-4 was validated and standardized in Germany by Löwe et al. [37]. In a sample of $\mathrm{N}=5003$, the PHQ-4 reached a Cronbach reliability score of $\alpha=0.82$.

\section{HEALTH-49}




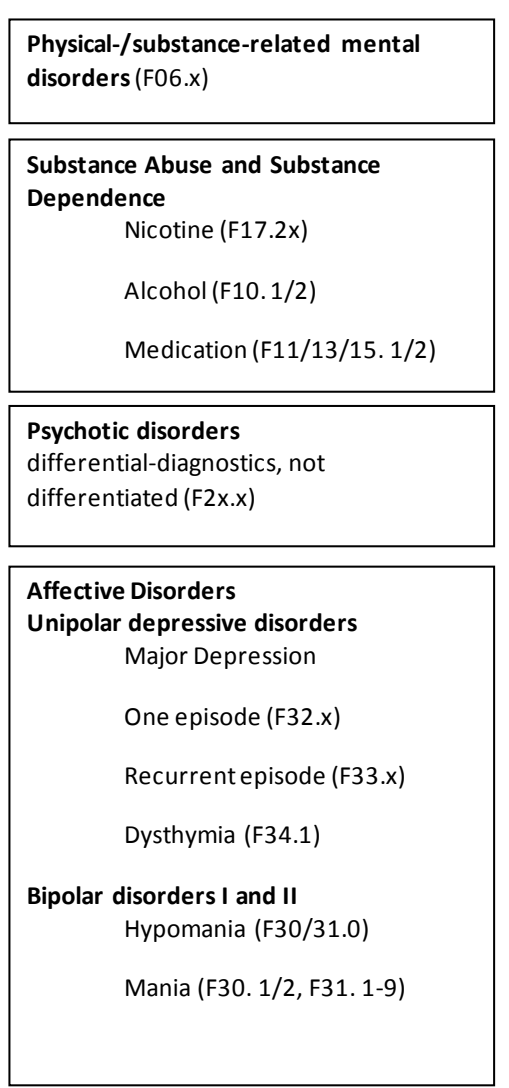

Posttraumatic stress disorder (F43.1)

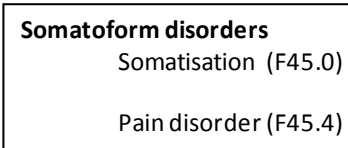

Anxiety disorders

Panic disorder (F41.0, F40.01)

Agoraphobia (F40.00)

Generalized anxiety disorder (F41.1)

Social anxiety disorder (F40.1)

Specific phobias (F40.2x)

Obsessive compulsive disorders (F42.x)

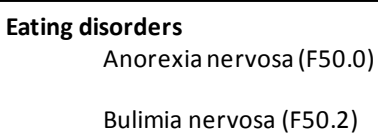

Figure 3. Diagnostic areas of the Composite International Diagnostic Interview, DIA-X Version 2.8 (Wittchen \& Pfister, 1997).

The questionnaire Hamburger Module zur Erfassung allgemeiner Aspekte psychosozialer Gesundheit für die therapeutische Praxis (HEALTH-49) is a 49-item self-assessment instrument that measures general aspects of psychosocial health [38]. It consists of 6 modules that can be applied independently and covers the following nine scales: somatic disorders, depression, mental well-being, difficulties in interaction, self-efficacy, activity and participation, social support and social strains. These items are rated on a 5 point Likert scale where $0=$ ("not" or “never"), 1 = (“few" or "infrequent"), 2 = (“middle" or "occasionally”), 3 = (“considerably" or "often”) and 4 = ("very" or "always").

HEALTH-49 reaches a consistent reliability (Cronbach's $\alpha>0.82$ ) for all the modules except social support and social strain (where Cronbach's $\alpha=0.76$ ). The average intercorrelation of the scales was found to be $\mathrm{r}=$ 0.38 .

\section{T-HEALTH-49}

A Turkish language version was developed and psychometrically tested [39], showing a satisfactory internal consistence (Cronbach's $\alpha$ for all scales $>0.71)$. The average intercorrelation of the individual scales $(r=0.36)$ also proved to be comparable to the original German language version $(r=0.38)$.

\section{GHQ-28}

The General Health Questionnaire was developed as a screening instrument to identify psychological distress among adults in primary care settings [40]. It consists of 28 items, which can be categorized in four subscales: somatic symptoms, anxiety/sleep disorders, social dysfunction, and severe depression.

Each of the seven items present on each subscale can be rated by those interviewed in a self-evaluation on a 4-point Likert scale where $0=$ ("not at all"), 1 = ("no more than usual"), $2=$ ("rather more than usual") and $3=$ ("much more than usual"). With a maximum possible total score of 84 points, a total score of 23 or higher indicates a heightened risk of psychosocial disorders. A second option for the evaluation is through a binary method, where the response of "not at all" and "no more than usual" are coded as 0 , while "rather more than usual" and "much more than usual" are coded as 1 . Here the cutoff point is 4 . The GHQ-28 has a very good internal reli- 
ability (Cronbach's $\alpha=0.9-0.95$ ) [41]. The average time to complete the questionnaire is approximately 5 minutes [42].

\section{Gambling addiction}

Two screening questions for gambling problems were presented in the survey. The first question stated: "Have you ever made a bet or played a game for money in your life?" If this question was answered with "no" then no gambling addiction could be present. If this question was answered with "yes", then the following question was asked: "Have you gambled or played for money on more than 10 days in your life?" Again, if the answer was "no" then no gambling addiction was possible and this survey section was completed. If the question was answered with "yes", then the participant completed the Lie/Bet questionnaire. The screening questions are based on results of epidemiological studies in Germany indicating a 99\% sensitivity for the screening of gambling related problems in the general population [43] [44].

\section{Lie/Bet Questionnaire}

The Lie/Bet Questionnaire is a screening instrument consisting of two items that is used to diagnose pathological gambling [45]. The two questions are: "Have you ever felt the desire to play for more money?" and "Have you ever had to lie about the extent of your gambling to people who are important to you?" These two questions were extracted from the DSM-IV criteria pertaining to gambling because they are the two best indicators for pathological gambling. If at least one of the two questions is answered with a "yes", then the Berliner Inventory for Gambling addictions (BIG) was applied.

\section{BIG}

The Berliner Inventar zu Glücksspielproblemen (Berlin Inventory for Gambling Addiction), is a 15-item screening instrument used to assess pathological gambling [46]. The items describe gambling related problems and symptoms of pathological gambling based on the DSM-IV. The questionnaire has been tested psychometrically and offers a valid and reliable measurement instrument for the detection of pathological gambling [47].

\section{Questionnaire for socio-demographic data and of utilization behaviour}

To assess the socio-demographic data and the utilization of the psychosocial healthcare system, a supplementary questionnaire was developed. For the sake of comparison, questions from the first [48] and second German national health survey [49] as well as the micro census of 2010 [50] were used. The questionnaire contains 50 questions: 32 pertain to socio-demographic information and 18 pertain to the utilization of psychosocial healthcare opportunities.

\section{Contact and documentation sheets}

For quality assurance, contact and documentation sheets were used that were adapted to the corresponding data collection processes in Hamburg and Berlin. The sheets were exclusively filled out by the interviewer to document problems arising during the interview and to maintain the quality of the interview evaluation. The sheets contain both non-responder questions and questions pertaining to the contact and interview data.

\section{Incentives}

The individuals who participated in the interview obtained compensation in the form of 10 Euro for every started hour of their participation, either in the form of a gift card (Hamburg) or in cash 10 Euro for the screening step and further 10 Euro for the main interview in the second step (Berlin).

\section{Translation of the survey instruments}

The CIDI DIA-X Version 2.8 was translated in a multi-step process that followed the TRAPD Team approach by Harkness (2008) [51]. Initially two Turkish native speakers with translation experience (working in parallel and independently from one another) translated all the items, including the answer choices and the interview instructions (translation phase). The two translations were compared by a Turkish speaking psychologist, who developed a temporary translation (advanced translation phase). In a further step (review phase) the temporary Turkish version of the CIDI was discussed and/or reviewed by the translation team in an item-by-item fashion. When there were disagreements or uncertainties within the team regarding the appropriate translation, three additional Turkish-speaking experts (a psychiatrist and two researchers) were consulted in writing to make translation suggestions. The translation of the CIDI was completed by discussing and combining the initial team and external expert translations (adjudication phase). The adjusted CIDI translation was then tested for the intelligibility of the question and answer items and the instructions. The test subjects $(n=6)$ were individuals living in Hamburg and Berlin with Turkish migration backgrounds, who selected Turkish as their language preference (the language they were most comfortable with) in this pretest. The final Turkish language version of the CIDI was developed through the application of several control loops within the team, based on language and pro- 
gramming problems that arose (i.e., comprehension difficulties, errors in filtering). During the translation and survey process, any problems pertaining to the practicability of the Turkish version of CIDI Version 2.8 were documented (documentation phase). The entire translation process took place over a period of approximately two months. A detailed description of the translation, the editing process and the feasibility analysis of the translated CIDI DIA-X Version 2.8 can be found in Dingoyan et al. (in review) [29].

With the exceptions of the (T-) HEALTH-49, the additional survey instruments (PHQ-4, GHQ-28 and gambling screening questions, and BIG) were translated unilaterally due to time and resource constraints, but were subjected to several correction and reviewing loops in discourse with the team.

\subsection{Statistical Methods}

\section{Power calculation}

A project pretest was used to identify feasibility issues when using the instruments.

The analysis for calculation of the required sample size have been calculated with the program nQuery Advisor 6.0 (Sample Size Tables for Proportions, 2007). The prevalence of mental disorders of the German population has been defined as a base of operations (Wittchen et al., 2000). The 4-week-prevalance of mental disorders has been determined for the clinical most important groups of diagnostic disorders: addiction disorders (F1 of the ICD-10, chapter V), affective disorders (F3), anxiety disorders including the somatoform disorders (F4), The necessary sample size is determined by the expected 4 week prevalence rate of $19 \%$, verified with a confidence interval of $+/-3.0 \%$ and a $95 \%$ confidence coefficient. As a consequence the minimum required target sample size is 662 patients.

Sampling and stratification

Administrative differences in each site required the use of multiple sampling strategies. Samples were collected using either a register of residents or a snowball approach. Reasons for nonparticipation and ineligibility were documented. In addition, information about non-responders (e.g., age and gender) was collected to examine any selective attrition effects.

Each study site defined a catchment area prior to recruitment. This catchment was representative of the region's Turkish population. The main aim of this approach is to estimate the overall prevalence of mental disorders in individuals with Turkish backgrounds as precisely as possible.

To reach a maximum representative sample of the regional community of individuals with Turkish migration backgrounds, a three dimensional strata was designed (gender: male/female; age: 18-29/30-49/50-65; educational background: low/middle/high). The strata were based on official regional population data (see Table 5).

Statistical analyses

To answer RQ 1, a feasibility analysis on the translated instrument was undertaken. As the study aimed to examine the prevalence and comorbidity rates of mental disorders in individuals with Turkish migration backgrounds (RQs 2 and 3), the data from both sites were analysed in a comprehensive statistical model. Mixed generalised linear models, with regional site as a random effect and stratum (age*sex*education) as a fixed effect, were used to estimate prevalence and comorbidity. In addition, the BLUP estimators returned by the model were used to analyse differences between the sites.

For all estimators, the corresponding confidence intervals were calculated. The estimated prevalence rates were projected to the total population of the participating cites based on the publicly available population statistics for individuals with Turkish migration backgrounds.

These prevalence estimations for mental disorders (point, 1-year and lifetime prevalence) in individuals with Turkish backgrounds in absolute figures at 95\% confidence intervals and predictors of mental disorders on the basis of binary logistic regression analyses (including affective disorders as variable criteria; and including age, gender, education, living situation, and partner situation as independent variables) were also calculated. Furthermore, calculation of odds ratios and confidence intervals, comorbidity rates and correlations to physical disorders were performed. Binary logistic regression analyses (utilization of health services as a dependent variable and the aforementioned independent variables) and calculation of odds ratios and confidence intervals were also performed. In addition, data from non-responders was analysed to identify differences between responders and non-responders.

To answer RQ 5, semistructured focus groups were conducted. The qualitative content analysis was based on the method of Mayring [52]. 
Table 5. Stratification of the sample in Hamburg and Berlin.

\begin{tabular}{|c|c|c|c|c|c|c|c|}
\hline \multicolumn{8}{|c|}{ Hamburg } \\
\hline & \multirow{2}{*}{\multicolumn{2}{|c|}{$\begin{array}{c}\text { Female } \\
\text { Age }\end{array}$}} & \multicolumn{5}{|c|}{ Male } \\
\hline & & & \multirow{3}{*}{$50-65$} & \multicolumn{3}{|c|}{ Age } & \\
\hline & \multirow[t]{2}{*}{$18-29$} & \multirow[t]{2}{*}{$30-49$} & & $18-29$ & $30-49$ & $50-65$ & \\
\hline \multicolumn{5}{|l|}{ Education } & & & \\
\hline low & 4 & 44 & 22 & 4 & 35 & 18 & 127 \\
\hline middle & 15 & 22 & 6 & 3 & 27 & 8 & 81 \\
\hline high & 22 & 49 & 7 & 27 & 56 & 7 & 168 \\
\hline Total & 41 & 115 & 35 & 34 & 118 & 33 & 376 \\
\hline \multicolumn{8}{|c|}{ Berlin } \\
\hline & \multicolumn{3}{|c|}{ Female } & \multicolumn{3}{|c|}{ Male } & \\
\hline & \multicolumn{3}{|c|}{ Age } & \multicolumn{3}{|c|}{ Age } & \\
\hline & $18-29$ & $30-49$ & $50-65$ & $18-29$ & $30-49$ & $50-65$ & \\
\hline \multicolumn{8}{|l|}{ Education } \\
\hline low & 13 & 54 & 33 & 3 & 15 & 12 & 130 \\
\hline middle & 17 & 27 & 5 & 9 & 18 & 4 & 80 \\
\hline high & 16 & 27 & 5 & 6 & 11 & 11 & 76 \\
\hline Total & 46 & 108 & 43 & 18 & 44 & 27 & 286 \\
\hline
\end{tabular}

\section{Discussion}

The currently available data in Germany does not provide reliable prevalence and comorbidity rates of mental disorders in individuals with Turkish migration backgrounds. Therefore, the main goal of this study was to assess the four-week, 12-month and lifetime prevalence of mental disorders in adults with Turkish migration backgrounds living in Germany. A further question examined was the treatment needs of this target group and their utilization of the healthcare system. Migration-specific methodological procedures were implemented for this study (i.e., implementation of focus groups, media campaigns, inclusion of key individuals and stakeholders, development of a bilingual field team and use of bilingual information and interview material, etc.).

Due to this bilingual focus, it was possible to include individuals in the study with limited German language proficiency from the beginning. The significance of this inclusion is evident because more than two thirds of those interviewed in the study preferred Turkish as their interview language. The questions and the answer options were read aloud by the interviewers; therefore, illiteracy was also not a reason for exclusion from the study.

The following main two limitations of the study were observed: 1) the differing recruitment methods between the two locations of Hamburg and Berlin and 2) the limited response and participation rates, despite the described measures undertaken to increase participation. Therefore, it is necessary to analyse and discuss the strengths and weaknesses of the study, as well as the representativeness of the results in further publications.

With the attainment of the target sample size $(\mathrm{N}=662)$ and the implementation of extensive face-to-face interviews, a reliable data basis concerning prevalence rates as well as treatment needs and utilization of the healthcare system could be provided. The following research topics for further analyses and investigations were related to this study:

- The inclusion of minority groups, which are difficult to access in research studies (reasons for barriers, resources, methodological procedures in project planning, sample recruitment and implementation of epidemiological studies as well as those pertaining to the attainability of representativeness, etc.).

- Culturally sensitive translation of survey instruments and investigation of their feasibility for the assessment of mental disorders in individuals with Turkish migration backgrounds and for further migrant groups in Germany. 
- Further assessments of prevalence rates (point, year, lifetime) in various migrant groups in Germany and comparing these to the host society.

- Identifying the level of mental disorder severity in individuals with Turkish migration backgrounds and other migrant groups in Germany.

- Identifying factors that promote and hinder individuals with Turkish migration backgrounds from accessing German health care services.

- Identifying predictors and risk factors affecting the development and course of mental disorders in individuals with Turkish migration backgrounds and other migrant groups in Germany

\section{Acknowledgements}

This study was part of the international research project "Orientation of the mental health care system towards the needs of migrants with mental disorders, 2009/11-2012/10”, supported by a grant from the Volkswagen Foundation (a German non-profit organization; funding code II/84 336). We gratefully thank the Volkswagen Foundation for funding this study. We also thank all of the participants and interviewers in our study, all supporters and the advisory board.

\section{Competing Interests}

The authors have no competing interests.

\section{Author Contribution}

The authors collectively drafted the study protocol and approved the final manuscript.

\section{References}

[1] United Nations, Department of Economic and Social Affairs. Trends in International Migrant Stock: The 2013 Revision. 2013.

[2] Eurostat: European Social Statistics 2013 Edition. 31. Luxembourg 2013. http://ec.europa.eu/eurostat/statistics-explained/index.php/Category:Population_and_social_conditions_-_statistical_pu blications

[3] UNHCR: UNHCR Global Trends 2014. UNHCR 2015. http://unhcr.org/556725e69.html

[4] Prince, M., Patel, V., Saxena, S., Maj, M., Maselko, J., Phillips, M.R. and Rahman, A. (2007) No Mental Health without Mental Health. Lancet, 370, 859-877. http://dx.doi.org/10.1016/S0140-6736(07)61238-0

[5] Wittchen, H.U., Jacobi, F., Rehm, J., Gustavsson, A., Svensson, M., Jönsson, B., Olesen, J., Allgulander, C., Alonso, J., Faravelli, C., Fratiglioni, L., Jennum, P., Lieb, R., Maercker, A., van Os, J., Preisig, M., Salvador-Carulla, L., Simon, R. and Steinhausen, H.C. (2011) The Size and Burden of Mental Disorders and Other Disorders of the Brain in Europe 2010. European Neuropsychopharmacology, 21, 655-679. http://dx.doi.org/10.1016/j.euroneuro.2011.07.018

[6] Kirkcaldy, B., Wittig, U., Furnham, A., Merbach, M. and Siefen, R.G. (2006) Health and Migration. Psychosocial Determinants. Bundesgesundheitsblatt Gesundheitsforschung Gesundheitsschutz, 49, 873-883. http://dx.doi.org/10.1007/s00103-006-0021-9

[7] Rechel, B., Mladovsky, P., Ingleby, D., Mackenbach, J.P. and McKee, M. (2013) Migration and Health in an Increasingly Diverse Europe. The Lancet, 381, 1235-1245. http://dx.doi.org/10.1016/S0140-6736(12)62086-8

[8] Kristiansen, M., Mygind, A. and Krasnik, A. (2007) Health Effects of Migration. Danish Medical Bulletin, 1, 46-7.

[9] Lechner, I. and Mielck, A. (1998) Die Verkleinerung des "Healthy-Migrant Effects”: Entwicklung der Morbidität von ausländischen und deutschen Befragten im sozioökonomischen Panel 1984-1992. Das Gesundheitswesen, 60, 715-720.

[10] Shuval, J.T. (1993) Migration and Stress. In: Goldberger, L.B. and Shlomo, B., Eds., Handbook of Stress: Theoretical and Clinical Aspects. Free Press, New York, 641-657.

[11] Groenemeyer, A. and Mansel, J., Eds. (2003) Die Ethnisierung von Alltagskonflikten. Leske + Budrich, Opladen. http://dx.doi.org/10.1007/978-3-322-99668-8

[12] Swinnen, S.G. and Selten, J.P. (2007) Mood Disorders and Migration. British Journal of Psychiatry, 190, 6-10. http://dx.doi.org/10.1192/bjp.bp.105.020800

[13] Grant, B.F., Stinson, F.S., Hasin, D.S., Dawson, D.A., Chou, S. and Anderson, K. (2004) Immigration and Lifetime Prevalence of DSM-IV Psychiatric Disorders among Mexican Americans and Non-Hispanic Whites in the United 
States. Results from the National Epidemiologic Survey on Alcohol and Related Conditions. Archives of General Psychiatry, 61, 1226-1233. http://dx.doi.org/10.1001/archpsyc.61.12.1226

[14] Alegria, M., Canino, G., Shrout, P.E., Woo, M., Duan, N., Vila, D., Torres, M., Chen, C.H. and Meng, X.L. (2008) Prevalence of Mental Illness in Immigrant and Non-Immigrant U.S. Latino Groups. The American Journal of Psychiatry, 165, 359-369. http://dx.doi.org/10.1176/appi.ajp.2007.07040704

[15] Takeuchi, D.T., Zane, N., Hong, S., Chae, D.H., Gong, F., Gee, G.C., Walton, E., Sue, S. and Alegría, M. (2007) Immigration-Related Factors and Mental Disorders among Asian Americans. American Journal of Public Health, 97, 84-90. http://dx.doi.org/10.2105/AJPH.2006.088401

[16] Breslau, J. and Chang, D.F. (2006) Psychiatric Disorders among Foreign-Born and US-Born Asian-Americans in a US National Survey. Social Psychiatry \& Psychiatric Epidemiology, 41, 943-950. http://dx.doi.org/10.1007/s00127-006-0119-2

[17] Vega, W.A., Sribney, W.M., Aguilar-Gaxiola, S. and Kolody, B. (2004) 12-Month Prevalence of DSM-III-R Psychiatric Disorders among Mexican Americans: Nativity, Social Assimilation, and Age Determinants. The Journal of Nervous \& Mental Disease, 192, 532-541. http://dx.doi.org/10.1097/01.nmd.0000135477.57357.b2

[18] Alderete, E., Vega, W.A. and Kolody, B. (2000) Effects of Time in the United States and Indian Ethnicity on DSMIII-R Psychiatric Disorders among Mexican Americans in California. The Journal of Nervous \& Mental Disease, 188, 90-100. http://dx.doi.org/10.1097/00005053-200002000-00005

[19] Hjern, A., Wicks, S. and Dahlman, C. (2004) Social Adversity Contributes to High Morbidity in Psychoses in Immigrants-A National Cohort Study in Two Generations of Swedish Residents. Psychological Medicine, 34, 1025-1033. http://dx.doi.org/10.1017/S003329170300148X

[20] Levecque, K., Lodewyckx, I. and Vranken, J. (2007) Depression and Generalized Anxiety in the General Population in Belgium: A Comparison between Native and Immigrant Groups. Journal of Affective Disorders, 97, 229-239. http://dx.doi.org/10.1016/j.jad.2006.06.022

[21] Bengi-Arslan, L., Verhulst, F.C. and Crijnen, A.A.M. (2002) Prevalence and Determinants of Minor Psychiatric Disorder in Turkish Immigrants Living in the Netherlands. Social Psychiatry \& Psychiatric Epidemiology, 37, 118-124. http://dx.doi.org/10.1007/s001270200003

[22] De Wit, M.A., Tuinebreijer, W.C., Dekker, J., Beekman, A.J., Gorissen, W., Schrier, A.C., Penninx, B.W., Komproe, I.H. and Verhoeff, A.P. (2008) Depressive and Anxiety Disorders in Different Ethnic Groups: A Population Based Study among Native Dutch, and Turkish, Moroccan and Surinamese Migrants in Amsterdam. Social Psychiatry and Psychiatric Epidemiology, 43, 905-912. http://dx.doi.org/10.1007/s00127-008-0382-5

[23] Razum, O., Zeeb, H., Meesmann, U., Schenk, L., Bredehorst, M., Brzoska, P., Dercks, T., Glodny, S., Menkhaus, B., Salman, R., Saß, A.C. and Ulrich, R. (2008) Migration und Gesundheit. Schwerpunktbericht der Gesundheitsberichterstattung des Bundes. Robert Koch-Institut, Berlin.

[24] Mösko, M., Dingoyan, D. and Schulz, H. (2015) Interkulturalität in der gesundheitlichen Versorgung. In: Koch, U. and Bengel, J., Eds., Enzyklopaedie Medizin Psychologie, Hogrefe, Göttingen, Band 2.

[25] Bermejo, I., Mayninger, E., Kriston, L. and Härter, M. (2010) Mental Disorders in People with Migration Background Compared with German General Population. Psychiatrische Praxis, 37, 225-232. http://dx.doi.org/10.1055/s-0029-1223513

[26] Glaesmer, H., Brähler, E., Wittig, U., Martin, A., Mewes, R. and Rief, W. (2009) Sind Migranten häufiger von psychischen Störungen betroffen? Eine Untersuchung an einer repräsentativen Stichprobe der deutschen Allgemeinbevölkerung. Psychiatrische Praxis, 36, 16-22. http://dx.doi.org/10.1055/s-2008-1067566

[27] Statistisches Bundesamt (2013) Bevölkerung und Erwerbstätigkeit. Bevölkerung mit Migrationshintergrund. Ergebnisse des Mikrozensus 2012. Fachserie 1, Reihe 2.2. Statistisches Bundesamt, Wiesbaden.

[28] Dingoyan, D., Schulz, H. and Mösko, M. (2012) The Willingness to Participate in Health Research Studies of Individuals with Turkish Migration Backgrounds: Barriers and Resources. A Qualitative Analysis of Focus Groups. European Psychiatry, 27, S4-S9. http://dx.doi.org/10.1016/S0924-9338(12)75701-2

[29] Dingoyan, D., Mösko, M., Imamoğlu, Y., von Wolff, A., Strehle, J., Wittchen, H.U., Schulz, H., Koch, U., Heinz, A. and Kluge, U. Development and Feasibility of the Computerized Turkish Edition of the Composite International Interview (DIA-X CIDI Version 2.8TR). International Journal of Methods in Psychiatric Research. (In Press).

[30] Statistisches Amt für Hamburg und Schleswig-Holstein (2012) Bevölkerung mit Migrationshintergrund in den Hamburger Stadtteilen Ende Januar 2012.

http://www.statistik-nord.de/publikationen/publikationen/presseinformationen/dokumentenansicht/bevoelkerung-mit-m igrationshintergrund-in-den-hamburger-stadtteilen-ende-januar-2012/

[31] Humpert, A. and Schneiderheinze, K. (2000) Stichprobenziehung für telefonische Zuwandererumfragen. Einsatzmöglichkeiten der Namensforschung. ZUMA-Nachrichten, 47, 36-64. 
[32] Wittchen, H.U. and Pfister, H. (1997) Instruktionsmanual zur Durchführung von DIA-X Interviews. Swets \& Zeitlinger, Frankfurt.

[33] American Psychiatric Association (2013) Diagnostic and Statistical Manual of Mental Disorders. 5th Edition, American Psychiatric Publishing, Arlington.

[34] World Health Organization (2013) International Statistical Classification of Diseases and Related Health Problems. 10th Revision, Edition 2012, World Health Organization, Geneva.

[35] Wittchen, H.U., Lachner, G., Wunderlich, U. and Pfister, H. (1998) Test-Retest Reliability of the Computerized DSM-IV Version of the Munich-Composite International Diagnostic Interview (M-CIDI). Social Psychiatry and Psychiatric Epidemiology, 33, 568-578. http://dx.doi.org/10.1007/s001270050095

[36] Reed, V., Gander, F., Pfister, H., Steiger, A., Sonntag, H., Trenkwalder, C., Sonntag, A., Hundt, W. and Wittchen, H.U. (1998) To What Degree the Composite International Diagnostic Interview (CIDI) Correctly Identify DSM-IV Disorders? Testing Validity Issues in a Clinical Sample. International Journal of Methods in Psychiatric Research, 7, 142155. http://dx.doi.org/10.1002/mpr.44

[37] Löwe, B., Wahl, I., Rose, M., Spitzer, C., Glaesmer, H., Wingenfeld, K., Schneider, A. and Brähler, E. (2010) A 4-Item Measure of Depression and Anxiety: Validation and Standardization of the Patient Health Questionnaire-4 (PHQ-4) in the General Population. Journal of Affective Disorders, 122, 86-95. http://dx.doi.org/10.1016/j.jad.2009.06.019

[38] Rabung, S., Harfst, T., Koch, U., Wittchen, H.U. and Schulz, H. (2007) "Hamburger Module zur Erfassung allgemeiner Aspekte psychosozialer Gesundheit für die therapeutische Praxis (HEALTH)”-Psychometrische Überprüfung eines neuen Selbstbeurteilungsinstruments zur multidimensionalen Erfassung psychosozialer Gesundheit. Physikalische Medizin, Rehabilitationsmedizin, Kurortmedizin, 17, 133-140. http://dx.doi.org/10.1055/s-2007-940198

[39] Mösko, M., Rabung, S., Tingir, B., Pradel, S., Ddippel, A., Winkeler, M., Schneider, J., Dahlbender, R.W., Koch, E., Schouler-Ocak, M., Koch, U. and Schulz, H. (2011) Psychometrische Überprüfung der türkischsprachigen Version der “Hamburger Module zur Erfassung allgemeiner Aspekte psychosozialer Gesundheit” (T-HEALTH-49). Psychotherapie, Psychosomatik, Medizinische Psychologie, 61, 503-511. http://dx.doi.org/10.1055/s-0031-1291337

[40] Goldberg, D. (1978) Manual of the General Health Questionnaire. NFER-Nelson, Windsor.

[41] Failde, I., Ramos, I. and Fernandez-Palacín, F. (2000) Comparison between the GHQ-28 and SF-36 (MH 1-5) for the Assessment of Mental Health in Patients with Ischaemic Heart Disease. European Journal of Epidemiology, 16, 311316. http://dx.doi.org/10.1023/A:1007688525023

[42] Sterling, M. (2011) General Health Questionnaire-28 (GHQ-28). Journal of Physiotherapy, 57, 259. http://dx.doi.org/10.1016/S1836-9553(11)70060-1

[43] Bühringer, G., Kraus, L., Sonntag, D., Pfeiffer-Gerschel, T. and Steiner, S. (2007) Pathologisches Glücksspiel in Deutschland: Spiel- und Bevölkerungsrisiken. Sucht, 53, 296-308. http://dx.doi.org/10.1024/2007.05.06

[44] Buth, S. and Stöver, H. (2008) Glücksspielteilnahme und Glücksspielprobleme in Deutschland: Ergebnisse einer bundesweiten Repräsentativbefragung. Suchttherapie, 9, 3-11. http://dx.doi.org/10.1055/s-2008-1042440

[45] Johnson, E.E., Hamer, R.M. and Nora, R.M. (1998) The Lie/Bet Questionnaire for Screening Pathological Gamblers: A Follow-Up Study. Psychological Reports, 83, 1219-1224. http://dx.doi.org/10.2466/PR0.83.7.1219-1224

[46] Grüsser, S.M., Hesselbarth, U., Albrecht, U. and Mörsen, C.P. (2006) Berliner Inventar zum Glücksspielverhalten (BIG). Unveröffentlichtes Manuskript.

[47] Heinz, A., Mörsen, C.P. and Seiferth, N. (2010) Implikationen biopsychosozialer Grundlagen der Glücksspielsucht für Prävention und Therapie. Abschlussbericht an die Senatsverwaltung für Gesundheit und Soziales des Landes Berlin. Klinik für Psychiatrie und Psychotherapie, Charité-Universitätsmedizin Berlin.

[48] Wittchen, H.U., Müller, N., Pfister, H., Winter, S. and Schmidtkunz, B. (1999) Affektive, somatoforme und Angststörungen in Deutschland-Erste Ergebnisse des bundesweiten Zusatzsurveys "Psychische Störungen”. Gesundheitswesen, 61, 216-222.

[49] Jacobi, F., Höfler, M., Strehle, M., Mack, M., Gerschler, M., Scholl, M., Busch, M.A., Maske, U., Hapke, U., Gaebel, W., Maier, W., Wagner, M., Zielasek, J. and Wittchen, H.U. (2014) Psychische Störungen in der Allgemeinbevölkerung. Der Nervenarzt, 85, 77-87. http://dx.doi.org/10.1007/s00115-013-3961-y

[50] Statistische Ämter des Bundes und der Länder (2009) Mikrozensus 2010—Stichprobenerhebung über die Bevölkerung und den Arbeitsmarkt und Arbeitskräftestichprobe 2010 der Europäischen Union. Statistisches Bundesamt, Wiesbaden.

[51] Harkness, J.A. (2008) Comparative Survey Research: Goals and Challenges. In: De Leeuw, E.D., Hox, J.J. and Dillman, D.A., Eds., International Handbook of Survey Methodology, Lawrence Erlbaum Associates, New York/London, 56-77.

[52] Mayring, P. (2002) Qualitative Inhaltsanalyse-Grundlagen und Techniken. 8th Edition, UTB Beltz Verlag, Stuttgart. 


\section{Submit or recommend next manuscript to SCIRP and we will provide best service for you:}

Accepting pre-submission inquiries through Email, Facebook, LinkedIn, Twitter, etc.

A wide selection of journals (inclusive of 9 subjects, more than 200 journals)

Providing 24-hour high-quality service

User-friendly online submission system

Fair and swift peer-review system

Efficient typesetting and proofreading procedure

Display of the result of downloads and visits, as well as the number of cited articles

Maximum dissemination of your research work

Submit your manuscript at: http://papersubmission.scirp.org/ 